\title{
Critical Study of Chinese Youth in the Perspective of BBC Media
}

\author{
Xin Zhou \\ Southwest University, Chongqing, 400715
}

Keywords: SPC, Control Charts, Process Capability

\begin{abstract}
This article conforms to the current development of the times, analyzes the image of the Chinese youth from the perspective of the BBC media, and studies the present state of the Chinese youth with a critical look. From the aspects of text, discourse practice and language practice respectively, this article discusses the Western mainstream media's view of the Chinese youth image and the hidden ideology behind the image construction of the Chinese youth.
\end{abstract}

\section{Introduction}

In today's era, young people are an important part of social development and they are also the necessary forces for national development, national stability and national development. With the improvement of China's economic status and overall national strength, China is receiving the unanimous attention of all countries in the world. In the meantime, as a viable force for China's development, Chinese youth are also increasingly receiving the attention of the Western media. Under this circumstance, BBC's reports on Chinese youth appear in our field of vision. Domestic media and audiences aroused heated discussion on this series of news reports, all kinds of different voices were pouring in. In this paper, with a critical glance, this article analyzes in depth the multiple dimensions of the Chinese youth image from the perspective of the Western media represented by the BBC, For later reference to relevant researchers.

\section{Critical discourse analysis and Fairchild discourse analysis of three-dimensional framework}

The concept of critical discourse (CDA) comes from the important conceptual analysis theory of the 1970s. The concept of critical thinking is not only the highlight of social behavior but also the construction idea of the whole society. On the basis of this, the critical discourse They think that knowledge is not derived directly from the experience of discourse producers, but also from the constructive relationship between language and discourse. In other words, knowledge and truth tend to exist only in discourse, and they are merely discourses of discourse. However, the language as the carrier of discourse is not an objective and realistic communicative medium, but also influenced by such factors as power, race, history, gender, context, culture and consciousness in the process of transmission. Therefore, the most important work of critical discourse is to reveal the ideology and rights struggle behind the language. In particular, it is necessary to fairly and critically view a series of negative emotions such as prejudice, discrimination and vilification in the language environment so as to ensure fair and accurate language.

Critical discourse is based on the discourse concept, the analysis of discourse as a multi-dimensional, multi-mode, multi-function of a social performance, and generally from historical, linguistic and cultural perspectives such as analysis and research. Therefore, the critical discourse has rich connotation and interdisciplinary characteristics. The trait of critical discourse that is not subject-disciplined fundamentally determines the richness of its framework and methodology. From the past to the current development and evolution, the most authoritative influence of the critical discourse can be divided into four kinds, namely, Fowler's Critical Linguistics, Fairclough's social and cultural dialectical relationship analysis, Wodak discourse history analysis and Van. Dijk Social Cognitive Analysis of these four. Among the four critical discourses, Fairchild's sociocultural contextual dialectic analysis has been identified as one of the 
fairest, biased and systematic discourse analysis. Fairchild believes that both discourse and discourse practice are three-dimensional systems composed of text, discourse and social practice. In the three-dimensional system, text is the result of discourse practice. Discourse practice is a process of text from generation to circulation to popularity. The first two are determined by the concept of social practice. Therefore, any discourse analysis contains three levels, namely, text, discourse practice, social practice. In these three, the analysis of the text should be the core of the discourse analysis concept, mainly focusing on such factors as syntax, vocabulary, text deconstruction and interpersonal relations. The outer level is the analysis of social practice, exploring the link between discourse, power and ideology. As a link between text analysis and social practice, discourse practice is at an intermediate level, which includes text production, distribution and consumption. Therefore, at this juncture, Fairchild constructed a three-dimensional framework of critical discourse analysis system, the specific process is: description - elaboration - analysis, that is, the formal description of the text language, the process of text discourse practice Explain and explain the deep relationship between discourse practice, social and cultural context and ideology [1].

This article systematically analyzes and studies the Chinese youth image in BBC media news report and text writing from the perspective of Fairclough's dialectical analysis of the cultural context. From the perspective of social context, ideology and text Conduct in-depth research and analysis.

\section{The BBC media perspective of Chinese young people a critical analysis}

The BBC usually uses a vocabulary selection strategy in its coverage of the image of China's youth, namely the ideological square. This term was first proposed by van.Dijk and refers to the selective conceptual tool that the text producer decides under various tactical directives, characterized by a positive ego and a negative other. [2]

In the BBC media-related text, this term is very common. For example, in "The Secret of China Survival of the Fittest," Billie, the chief man, often explained the attitude of Chinese youth to online games: "For our youth, online games are just moderate leisure games, in addition, the same episode, the host introduced to the Chinese youth face the pressure of learning, as if to mention: "The learning atmosphere of our youth Is relaxed and happy, but the study of Chinese youth is from morning to night, can not stop ... ... "Also, in the" Chinese secret - desperate love ", the host introduced the Chinese youth marriage values, very deliberately mentioned: "In our country, young people simply pursue love only, without the conditions of marriage, but the marriage of Chinese youth is only based on the material basis, the Chinese men generally lack a sense of security and stability. ... "Obviously, in the BBC's" Chinese Secret "text, the BBC's choice of language vocabulary has a dual nature, giving a more general picture of the Chinese youth and using different words They are described young British and Chinese youth. This kind of behavior differentiates and generalizes the images of young people in Britain and of China, and makes use of such differentiation and generalization to subtly influence the establishment of false perceptions of the Chinese youth image by the BBC media audience. As a result, it is also conceivable that the audiences under the influence of the BBC have been stereotyped as obscure and vague about the Chinese youth [3].

The textual structure is a form that the text producer presents the text to the audience, which fully shows the perspective of the textual writer as well as the position idea. By structuring different textual contents, the important information in the text can be highlighted by the textwriter, receiving the attention and attention of the audience. In contrast, text writers can also background some of the important information and content they want to hide. In the process of "informatization" or "being informatized", the text writer can guide the audience to look at the problem from his perspective and analyze the text content. Therefore, the critical analysis of the textual structure is an effective way to reveal the self-prejudice, discrimination and negative emotions of the text writer.

Taking the BBC's recent news reporting structure as an example for analysis, the BBC host focused on the current situation of the addicted friends of Chinese teenagers, the life of teenager's online games and the pursuit and obsession with users. However, reports of young Chinese who are 
active, hard-working, active, innovative and brave are all very rare, and the avoidance means are very clear. From this, we can see that the prominence of informative content in such news texts is that "all Chinese young people are addicted to online games." A negative image has been established and the scope of influence expanded indefinitely. However, some positive and hard-working positive messages from the Chinese youth have been completely ignored. Under the $\mathrm{BBC}$ news reports, the Chinese youth have been identified as a group image that does not make progress and decadent. [4]

\section{The BBC media criticizes the reasons for the negative image of China's youth building}

The reason why the Western media represented by the BBC is keen to discredit the image of the Chinese youth is that discrediting the image of China in addition to the existing image of the Chinese youth itself is one of the important reasons why they conduct such acts. Since the founding of new China, the western countries have all along maintained their allegiance to China for winning and losing. The Western world holds a market-oriented attitude toward the rise of Chinese forces and its concepts have not been transformed. Under the influence of this situation, the most common method used by western countries is to use their own media power to enlarge some problems that have emerged in China's development so as to vilify the image of certain groups in China and China in order to curb China's development. purpose. It can be said that the prejudices on the image of China's young people like the BBC and other Western media mainly cover up the uneasiness of the rising of the Chinese forces and seek excuses and ventures for the weakness of their own development.

The discredit of the image of China's youth is closely linked with the "Western concept of center" represented by the BBC's media. Western countries generally believe that values, political systems, and forms of life in western capitalist societies are global applicable civilizations systems. As long as they are different from the direction and thinking of their civilized social system, they are all regarded as heresy elements of their ideas. Is standing on the opposite side of the enemy. It can be said that this factor of prejudice has been deeply integrated into the concept of the Western world from its birth to the present. Therefore, it is precisely because of the "western center concept" that the Chinese youths were generally shaped as the decadent and unsympathetic negative images in the press related reports and text writing of the BBC media [5].

\section{The critical thinking of the Chinese young people shaping the image of the BBC media}

Since the development of the new era, Chinese youth have generally been embraced by higher education and therefore have enjoyed different degrees of improvement in education and knowledge. However, due to the invasion of western values, the construction of social values system of adolescents has been impacted, ideological standards and code of conduct have been affected to varying degrees, resulting in the emergence of morals, confusion and ideological deviation, all of which have caused the western BBC The media attention, and hype about the negative image. As a result, contemporary Chinese youth are exposed to the world's readers with images of chaotic values, which can not objectively reflect the true face of the current Chinese youth image but only reveal the code of conduct for the power of western media hegemonist discourse [6]. In response to this phenomenon, young Chinese should spontaneously resist the invasion and vilification of Western media thoughts and correctly understand their own image. To promote the excellent and positive aspects of the Chinese youth, establish the correct values of their lives, and move forward in the right direction without wavering their own behavioral concepts so as to avoid discrediting the Chinese youth image by a group of media such as the BBC in the West. The Chinese media should take the lead in setting examples and vigorously describe and praise the spiritual image and positive image of elites (such as young artists, young athletes, etc.) in our youth groups and set a good example and direction for our youth. The establishment of China's youth image is not only a protest against the smear of the BBC and other western media, but also one of the necessary steps for developing China and building an excellent foreign image for China [7]. 
The competitiveness of Chinese youth can mainly be highlighted from the following aspects: First, the performance of the Chinese youth sports arena. Sports have always been the hot topics covered by foreign media. News reports headed by the BBC reached their peak at the 2012 Olympic Games. In these reports, there are more ink paintings of Chinese young players. In addition, reports of outstanding Chinese athletes are also emerging in the international arena such as the United States. It can be seen that relevant media such as the BBC do not mean generous praise from Chinese athletes and maintain a certain degree of recognition on the athletic ability and personality qualities of Chinese athletes. Therefore, this approach can effectively shape the youth groups in China Excellent competitive image. Second, overseas famous Chinese outstanding young people's reports. Such as Lang Lang and other representative contemporary Chinese youth groups, enjoy a certain degree of international recognition and exposure, their excellent artistic skills won the BBC and other media and audience alike praise and recognition of these outstanding young people are contemporary Chinese youth The guarantee of competitiveness can maximize the image of young people in China and become the driving force for the development of China. Thirdly, in the process of Internet development, the development and progress of Internet technology are attracting the attention of all countries. The contribution of Chinese youth in this high-end Internet technology can not be underestimated. This is an important way for China's youth image subversion It is also an important channel for the Chinese youth to cast their shadow on the new future [8].

\section{Conclusion}

This article analyzes Faircula's critical discourse and the three-dimensional framework, shaping the image of China's youth. Today's Chinese youth, as the representatives of China and the creators of China's image, must always pay attention to their own image and avoid being eroded by Western media such as the BBC to avoid the decadent, passive and aggressive thinking and establish a correct outlook on life, Values, marriage and wealth. At the same time, we should also pay attention to the coverage of the Chinese youth by the BBC's Western media and judge whether there is any false discourse among them. We should remind the broad masses of the young people to keep a clear head and proceed from their own advantages to avoid weaknesses in order to brainwash Western thinking. Spread Chinese voices, actively shape the image of the Chinese youth and contribute their own strength to the shaping of the Chinese youth image worldwide.

\section{References}

[1] Wang Yuhang, Song Chengfang. Journal of Nanjing Social Sciences, 2017, (05): 103-110 (in Chinese). Journal of Nanjing University of Science and Technology (Social Science)

[2] Yang Ying, Pan Mengqi, Steve Hewlett. The New Turn of the BBC Chinese Discourse - An Interview with Steve Hewlett [J]. Journal of the Global Media, 2016,3 (02): 130-133.

[3] Hutunan. BBC Grammatical Metaphor Study of Contextual Discourse [D]. Guangxi Normal University, 2015.

[4] Li Sisi. Stylistic Analysis of BBC News [D]. Taiyuan University of Technology, 2013.

[5] Ye Yanfang. "China Youth Daily" presents the "90 after" image [J]. News World, 2011, (12): 163-164.

[6] Wang Xiaoguang. The Characteristics and Changes of Young Media Images - Based on the Content Analysis of China Youth Magazine (1980-2009) [J]. Chinese Youth Studies, 2011, (04): 54-60.

[7] Ni Jian. International Communication and the Image of Chinese Youth [J]. World Knowledge, 2010, (23): 49-51.

[8] Xu Ke. Characteristics of "90 Hou" Image in Network Media - A Case Study of "China News" and "China Youth Online" "Xinhua Net" [J]. Journal of Shandong Youth University of Politics, 2011,27 (04)): 38-41. 